\title{
Chronic Regional Multifocal Osteomyelitis RE: SAPHO syndrome: A Radiological Case Report
}

\section{Dear Editor,}

It was with great interest we came across case report entitled "SAPHO syndrome: A Radiological Case Report" in the Jan-Mar 2020 (Volume 30, Issue 1). ${ }^{[1]}$ The article has succinctly detailed SAPHO syndrome with spectrum of clinical and imaging findings. A brief reference was also made to colloquially known paediatric equivalent i.e., Chronic Regional Multifocal Osteomyelitis (CRMO), it is in this regard we wish to expand on the previous article with our findings and observations of a known case.

A 10-year-old boy presented to us with on and off pain in the right knee since 4 months with new onset swelling and exacerbation. He played basketball and football for his school team, but increasing pain was impairing his movement on the playing field. There was no history of known trauma. On clinical exam, there was slight swelling along the knee with redness and significant tenderness on touch. The remainder of the clinical examination was normal. The initial lab non-significant elevated WBC count and ESR.

The radiograph [Figure 1] of the right knee showed an aggressive permeative lesion with an ill-defined

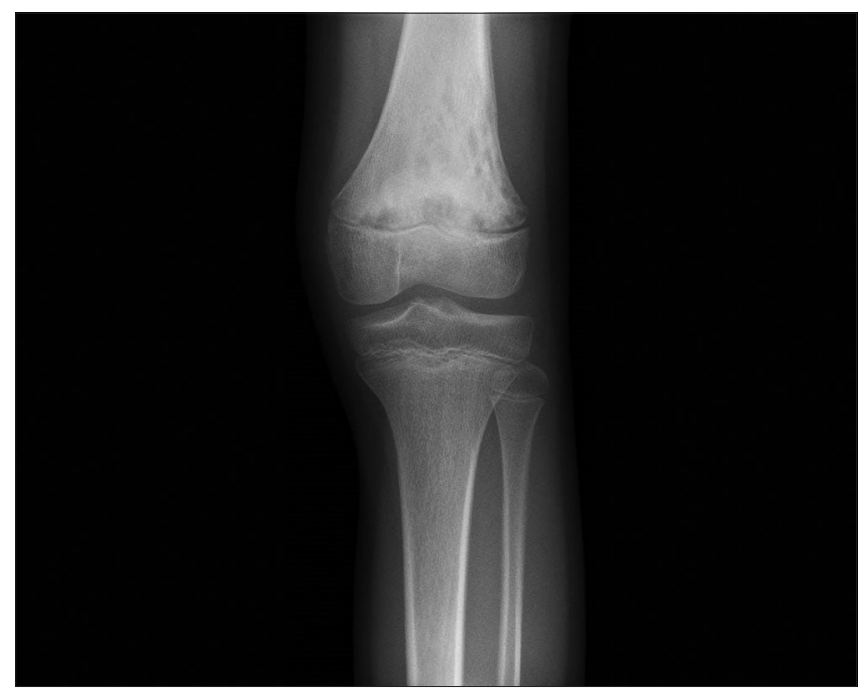

Figure 1: AP radiograph of right knee. There is an aggressive permeative lesion with wide zone of transition involving the distal metadiaphyseal region of the femur with "Codman's triangle" type of periosteal reaction margin and wide zone of transition involving the distal metadiaphyseal region of the femur with "Codman's triangle" appearance of periosteal reaction. In view of the clinical course and imaging findings possible differentials included Osteosarcoma, Ewing's sarcoma or unlikely Osteomyelitis.

Surprisingly, when CXR [Figure 2] on admission was reviewed, we saw sclerosis and cortical thickening along the posterior aspects left ribs $\left(6^{\text {th }}-8^{\text {th }}\right)$. This changed our differential to possible Multifocal osseous lymphoma versus unlikely widespread Langerhans cell histiocytosis.

A minimally invasive open approach biopsy of the femoral lesion showed no evidence of tumor or infection. Serology for typical and atypical infections was also negative. At this point, the diagnosis of CRMO was suspected and a whole body scintigram was obtained [Figure 3]; with scan showing uptake along posterior aspects of lower left ribs and right lower end of femur confirming our suspicion.

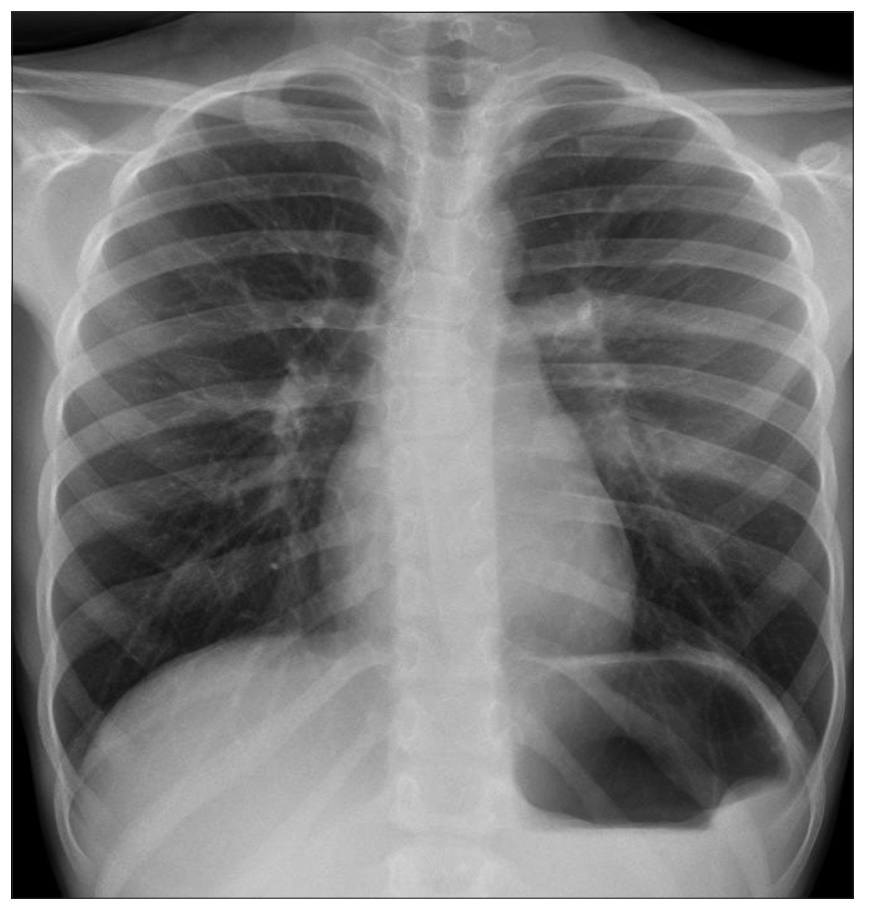

Figure 2: CXR. There is sclerosis and cortical thickening along the posterior aspects left ribs $\left(6^{\text {th }}-8^{\text {th }}\right)$ 


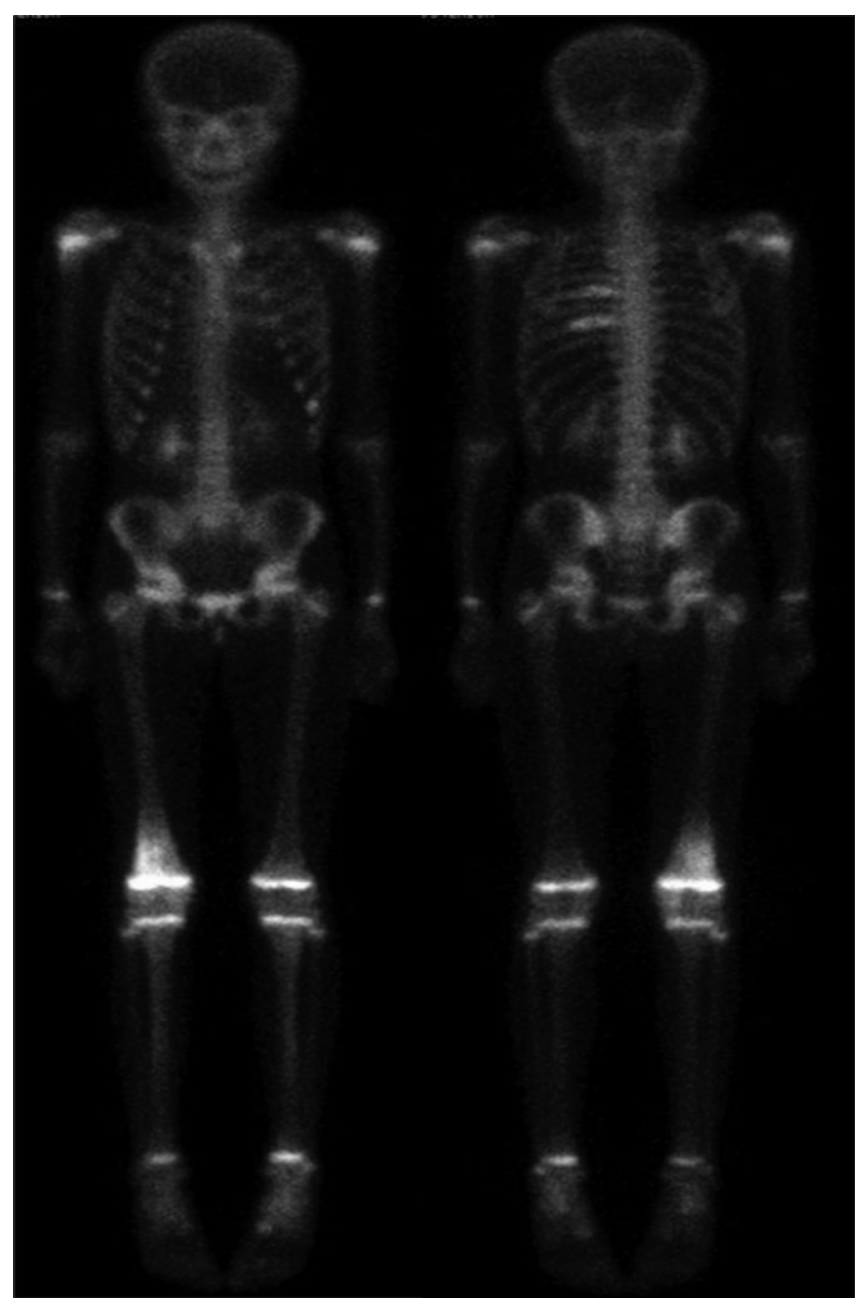

Figure 3: Technetium $99 \mathrm{~m}\left({ }^{99 \mathrm{~m} T \mathrm{~T})}\right.$ ) bone scan. Anterior and posterior projections show increased uptake in the lower end of right femur and along posterior end of left ribs

CRMO is thus an extremely rare presentation with unknown pathogenesis. It is largely believed to be slow response to an undetected infection versus a sequela to autoimmune condition. ${ }^{[2]}$ The disease being a diagnosis of exclusion is a significant challenge with multiple aforementioned differential diagnoses. A combination of imaging, clinical input, and adherence to a proposed diagnostic criteria improves confidence in cases. ${ }^{[3]}$ Treatment involves combination of anti-inflammatory medication with bisphonates. ${ }^{[4]}$ A timely diagnosis of CRMO presents us with an opportunity to spare a paediatric patient from significant number of unnecessary investigations, antibiotics and repeated biopsies.

\section{Declaration of patient consent}

The authors certify that they have obtained all appropriate patient consent forms. In the form the patient(s) has/have given his/her/their consent for his/her/their images and other clinical information to be reported in the journal. The patients understand that their names and initials will not be published and due efforts will be made to conceal their identity, but anonymity cannot be guaranteed.

Financial support and sponsorship

Nil.

\section{Conflicts of interest}

There are no conflicts of interest.

\section{Abhijeet Taori¹, Divya Malpani²}

${ }^{1}$ Consultant Radiologist, Suyash Hospital, ${ }^{2}$ Consultant Radiologist, Apollo Hospital, Indore, Madhya Pradesh, India. E-mail: abhijittaori@gmail.com

\section{Bibliography}

1. Singh A, Ranjan R. SAPHO syndrome: A radiological case report. Indian J Radiol Imaging 2020;30:84-8.

2. Khanna G, Sato TSP, Ferguson P. Imaging of chronic recurrent multifocal osteomyelitis. Radiographics 2009;29:1159-77.

3. Fritz J, Tzaribatchev N, Claussen CD, Carrino JA, Horger MS. Chronic recurrent multifocal osteomyelitis: Comparison of whole-body MR imaging with radiography and correlation with clinical and laboratory data. Radiology 2009;252:842-51.

4. Roderick MR, Shah R, Rogers V, Finn A, Ramanan AV. Chronic recurrent multifocal osteomyelitis (CRMO)-advancing the diagnosis. Pediatr Rheumatol Online J 2016;14:47.

This is an open access journal, and articles are distributed under the terms of the Creative Commons Attribution-NonCommercial-ShareAlike 4.0 License, which allows others to remix, tweak, and build upon the work non-commercially, as long as appropriate credit is given and the new creations are licensed under the identical terms.

\begin{tabular}{|l|l|}
\hline \multicolumn{2}{|c|}{ Access this article online } \\
\hline Quick Response Code: & \\
\hline & Website: \\
\hline & www.ijri.org \\
\cline { 2 - 3 } & DOI: \\
\hline
\end{tabular}

Cite this article as: Taori A, Malpani D. Chronic regional multifocal osteomyelitis RE: SAPHO syndrome: A radiological case report. Indian J Radiol Imaging 2020;30:533-4.

Received: 05-May-2020

Revised: 05-May-2020

Accepted: 31-Aug-2020 Published: 13-Jan-2021

๑ 2021 Indian Journal of Radiology and Imaging | Published by Wolters Kluwer - Medknow 